\title{
AutiPECS: Mobile Based Learning of Picture Exchange Communication Intervention for Caregivers of Autistic Children
}

\author{
Ahmad Sofian Shminan ${ }^{1}$, Rabiatu Adawiyah Adzani², Sabariah Sharif ${ }^{3}$ and Nung Kion Lee ${ }^{4}$ \\ 1,2,4 Faculty of Cognitive Sciences and Human Development, \\ Universiti Malaysia Sarawak, 94300 Kota Samarahan, Sarawak, Malaysia. \\ ${ }^{3}$ School of Education and Social Development, \\ Universiti Malaysia Sabah, 88400, Sabah, Malaysia. \\ Email: 1'sasofian@unimas.my, ${ }^{2}$ adawiyah.dzani@gmail.com, ${ }^{3}$ sabariah@ums.edu.my, ${ }^{4}$ nklee@unimas.my
}

\begin{abstract}
The goal of this study is to develop and assess a mobile-based learning concerning the Picture Exchange Communication (PECS) for Autism Spectrum Disorder (ASD) children's caregivers. Being an inexpensive intervention, the PECS has been proposed by other parents who have practised it on their children with non-verbal and behavioral disabilities. The underlying motivator for this mobile application is to guarantee that autistic children can have a better alternative intervention through the PECS approach so that they would not rely on the therapist a great deal or go to the autism center which is often costly. Fundamentally speaking, this mobile application elaborates on the user requirements which include PECS introduction, the characteristics, initial preparations, strategies and the activities. Instructional System Design (ISD) functions as the methodologies that help create the mobile-based learning. The system design has five stages namely the analysis, design, development, implementation and evaluation. These stages better known as ADDIE have the purpose to ensure that user will attain the goals of the instruction for the entire process. Lastly, to examine the content and the user interface design for this mobile application, a formative evaluation was conducted, aided by the usability testing by questionnaires and short instructed interviews. With the application of the ADDIE principles and guideline of Human-Computer Interaction (HCI), the best combination of causes of the AutiPECS had been developed properly. In sum, this research has been found to achieve the objectives. The content had been assessed by the expert, and the caregivers know how to adopt D.I.Y concepts as they are working on the learning materials. Future works may also be able to take more advantage of the AutiPECS 2.0 version where they can develop the mobile-based learning of PECS in the extended content and pay more attention to more specific case studies so that the caregivers know how to use PECS with the special children everyday.
\end{abstract}

Keywords-autism; picture exchange communication, mobile based learning; intervention; parents

\section{INTRODUCTION}

Autism was introduced by Leo Kanner [1] in his research of Early Infantile Autism in 1943. He defined autism as a deficit behavior that has less social interaction and development. In Greek, Autism is "autos" means "self" and the creation of their own world according to their imagination. In 2011, Mills and Marchant [2] describe autism as a "spectrum of neurodevelopmental conditions, present from very early life, which disrupt the development of social behavior and communication". There are three domain characteristics that are mostly shown in ASD like "social reciprocity, communication, and restricted and repetitive behaviors (RRBs) and interests" [3]. Generally, their social interaction is very low because they are more likely to be alone, where they never showed up or wanted to interact with people around them. Moreover, the autistics have difficulty using stereotyped phrases including intonation in communication with people and they tend to have fewer facial expressions like avoiding eye contact with others. The repetitive and restricted behaviors and interests of autistic children are evident when they repeat the actions like spinning objects, being strict with their schedule (i.e. daily routine) and have unusual interests in something (i.e. Focus on one object). Due to this situation, it is harder for autistics to adapt to the new environment.

Parents that have autism children mostly have difficulties where every day they need to adjust their daily activities and pay extra attention to their autistic children. Every family has their own vision when it comes to handling their autistic children. According to Banach, Iudice, Conway, \& Couse in year 2010 [4], the family's reactions after receiving their autistic children's diagnosis results are " $52 \%$ felt relieved, $43 \%$ felt grief and loss, $29 \%$ felt shock or surprise, and 10\% felt self-blame". Although the parents felt relieved with the diagnosis, the stress that they feel to raise the autistic children can still be overwhelming. The main effect on stressful for parents with autistic children is the basic need of autistic where it produces the frustration between two parties [5]. This is because the parents tend to worry that their children cannot communicate verbally and their high vulnerability may be harmful to the children. Thus, they need to pay attention consistently to their children.

Another stressful impact on the parents is their children's future [6]. They might be scared as they plan for the child's future and find ways of proper care because some of the children depends on their developmental ability, need an assist in toileting and bathing [5]. Autism Society in 2011 [7] stated that the other family members are not capable of taking care of the autistic individual if their parents are not able to take care of their child. This explains why the parents tend to feel stressed about their autistic children's future. The acceptability by the community is also one of the effects that parents must go through - it is a fact that sometimes, members of the community do not understand or are not sensitive of the autistic behaviors [5]. This negative perspective will leave 